\title{
A role of local VTA GABAergic neurons in mediating dopamine neuron response to nicotine
}

\author{
Ekaterina Morozova ${ }^{1 *}$, Maxym Myroshnychenko ${ }^{2}$, Marie Rooy ${ }^{3}$, Boris Gutkin ${ }^{3,4}$, Christopher C Lapish ${ }^{5}$, \\ Alexey Kuznetsov ${ }^{6}$
}

From 24th Annual Computational Neuroscience Meeting: CNS*2015

Prague, Czech Republic. 18-23 July 2015

The local circuitry of the tegmental area (VTA) consists primarily of dopamine (DA) and GABA neurons. Interactions between DA and GABA neurons are critical for regulating DA neuron activity, and thus DA efflux throughout the brain. One striking example that demonstrates the significance of local interactions between DA and GABA neurons is related to nicotine reinforcement. Experimentally, it was shown that activation of nicotinic acetylcholine (nAch) receptors on GABA neurons by Ach leads to an increase in both firing and bursting of the DA neuron, while nicotine produces an opposite effect [1]. In order to investigate the mechanism of this GABAmediated effect, we created a biologically plausible model of local VTA microcircuitry. The model network consists of a population of GABA neurons innervating one DA neuron. DA neuron dynamics are described by a conductance based model; which includes intrinsic and synaptic currents conducted by NMDA, AMPA, GABA, and nAch receptors. GABA neurons that are described by WangBuszaki equations provide inhibitory drive to the DA neuron. Excitatory inputs (Glu and Ach) to DA and GABA neurons are modeled as Poisson-distributed spike trains. Ach pulses act as synchronizing inputs to a population of GABA neurons, due to a transient activation of GABA nAch receptors, while nicotine persistently activates nAch receptor, causing an increase in firing frequency of GABA

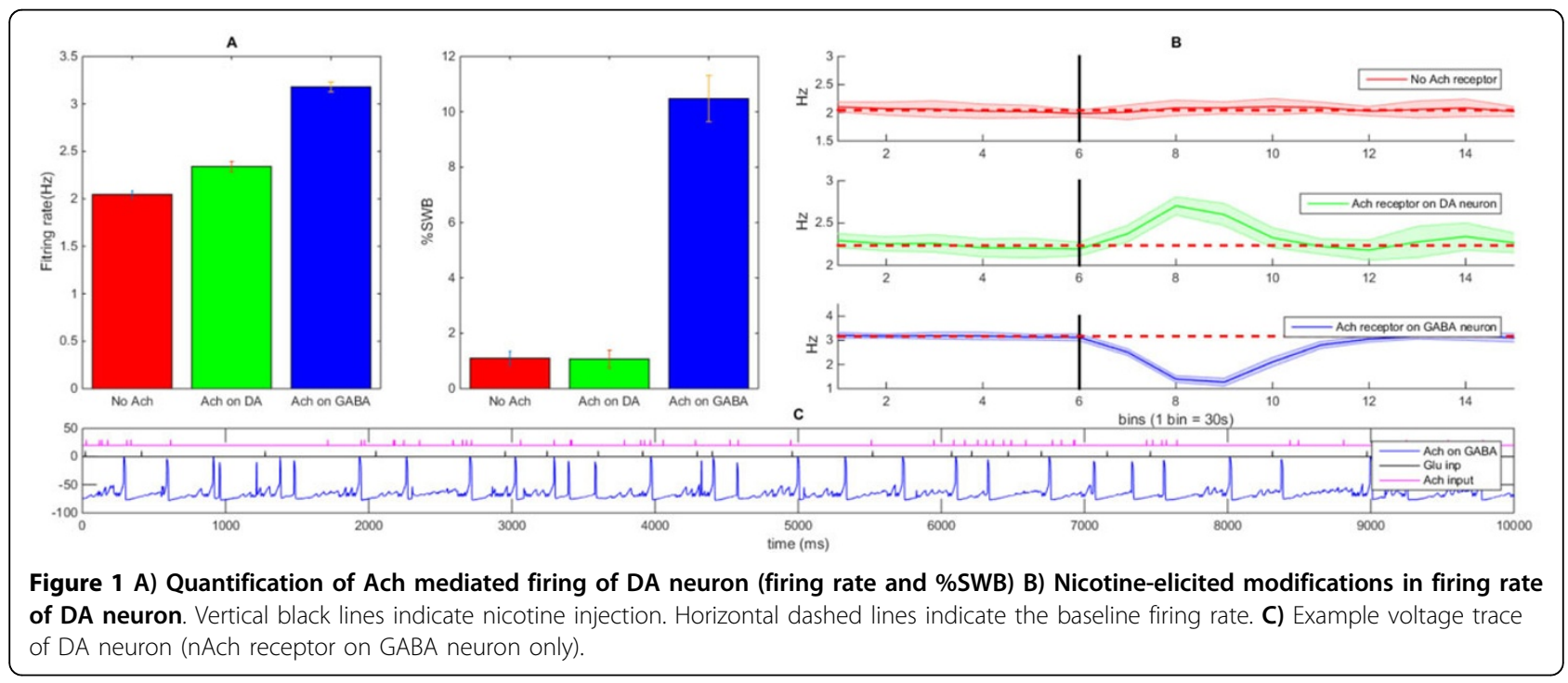

\footnotetext{
* Correspondence: emorozov@indiana.edu

'Department of Physics, Indiana University, Bloomington, IN, 47405, USA

Full list of author information is available at the end of the article
} 
neurons. Modeling revealed that synchronization of GABA neurons by cholinergic input could provide a mechanism for the elevation of DA neuron firing frequency and bursting. Synchronized GABA inputs act via phasic disinhibition that promotes rebound spikes, but is conditioned on the presence of depolarizing currents to the DA neuron. The opposite effects of nicotine applied to the GABA neuron only (decrease in firing and bursting of DA neuron), could be the result of desynchronization in population of GABA neurons, produced by tonic activation of nAch receptor. A desynchronized GABA population provides constant inhibition to the DA neuron that suppresses firing (see Figure 1). These data highlight the important and powerful role local circuit dynamics VTA. Furthermore, synchrony amongst GABA neurons seems to be a critical intermediary that regulates DA neuron activity and, by extension, DA release throughout the brain.

\section{Authors' details}

'Department of Physics, Indiana University, Bloomington, IN, 47405, USA.

${ }^{2}$ Program in Neuroscience, Indiana University, Bloomington, IN, 47405, USA.

${ }^{3}$ Group of Neural Theory, ENS, Paris, 75005, France. ${ }^{4}$ National Research

University Higher School of Economics, Moscow, 101000, Russia. ${ }^{5}$ Addiction

Neuroscience Program, IUPUI, Indianapolis, IN, 46202, USA. ${ }^{6}$ Department of

Mathematics, IUPUI, Indianapolis, IN, 46202, USA.

Published: 18 December 2015

\section{Reference}

1. Tolu S, Eddine R, Marti F, David V, Graupner M, Pons S, Baudonnat M, Husson M, Besson M, Reperant C, et al: Co-activation of VTA DA and GABA neurons mediates nicotine reinforcement. Molecular Pshyciatry 2013, 18:382-393.

doi:10.1186/1471-2202-16-S1-P137

Cite this article as: Morozova et al: A role of local VTA GABAergic neurons in mediating dopamine neuron response to nicotine. $B M C$ Neuroscience 2015 16(Suppl 1):P137.

\section{Submit your next manuscript to BioMed Central} and take full advantage of:

- Convenient online submission

- Thorough peer review

- No space constraints or color figure charges

- Immediate publication on acceptance

- Inclusion in PubMed, CAS, Scopus and Google Scholar

- Research which is freely available for redistribution

Submit your manuscript at www.biomedcentral.com/submit
C Biomed Central 